\title{
Tecnologias Assistivas no Ensino de Física para Alunos com Deficiência Visual: um estudo de caso baseado na audiodescrição
}

\author{
Assistive Technologies in Physics Teaching to Visually Impaired \\ Students: a Case study based on audio description
}

Priscila Valdênia dos Santos ${ }^{1}$

Gisllayne Cristina de Araújo Brandão²

1Universidade Federal do Recôncavo da Bahia (UFRB), Centro de Formação de Professores, Amargosa, BA, Brasil.
Autora correspondente: priscilavs65@ufrb.edu.br
${ }^{2}$ Universidade Federal do Rio Grande do Norte (UFRN), Instituto Metrópole Digital, Natal, RN, Brasil.

Resumo: Este trabalho apresenta um estudo sobre o uso da audiodescrição como tecnologia assistiva incorporada ao processo ensino-aprendizagem de física para um aluno do ensino superior com deficiência visual. Após a inserção de alguns tipos de tecnologias assistivas, observou-se que a barreira comunicacional persistia, impedindo o estudante de entender plenamente o conteúdo, resultando em grande dependência dos seus colegas e da tutora presencial. Assim, o objetivo da pesquisa é verificar como a audiodescrição incorporada ao contexto educacional pode contribuir para o aprendizado de física dos estudantes universitários com deficiência visual. Após o acompanhamento de cada etapa, em que diferentes tecnologias assistivas foram utilizadas, realizou-se a coleta de dados qualitativos, mediante aplicação de um questionário semiestruturado com o discente e sua tutora. A análise demonstrou que a audiodescrição proporcionou ao aluno uma maior autonomia e acentuada melhora em seu rendimento acadêmico, favorecendo condições para o exercício de sua cidadania plena.

Palavras-chave: Ensino de física; Deficiências da visão; Ensino superior; Inclusão escolar.

\begin{abstract}
This paper presents a case study on the use of audio description as assistive technology incorporated into the physics teaching-learning process with a visually impaired undergraduate student. After the insertion of some types of assistive technologies, we observed that the communication barrier was still present and preventing the student from completely understanding the content, thus resulting in his dependence on peers as well as on the tutor. The objective of this research is to verify how the audio description incorporated into the educational context can contribute to the learning of physics by visually impaired university students. After monitoring each step, qualitative data were collected by applying a semi-structured questionnaire with the student and his tutor. Data analysis showed that the audio description, combined with the tactile material, has provided the student with greater autonomy and remarkable improvement on his academic performance, favoring conditions for the exercise of his full citizenship.
\end{abstract}

Keywords: Physics teaching; Visual Impairment; Higher Education; Scholar inclusion.

Recebido em: 09/11/2019

Aprovado em: 30/04/2020 


\section{Introdução}

A Organização Mundial de Saúde (OMS) estabelece que uma pessoa seja considerada deficiente visual se for privada, em parte ou totalmente, da capacidade de ver. Camargo (2005), por sua vez, complementa que cega é aquela pessoa que apresenta pouca ou nenhuma percepção da luz, já o indivíduo com baixa visão é aquele que tem visão de curto alcance, enxergando objetos a poucos centímetros de distância. O autor ainda pontua que no contexto educacional a pessoa com baixa visão diferencia-se da cega pelo uso de material impresso ampliado, em contraponto ao uso da escrita Braille1.

O Censo demográfico divulgado no ano 2000 pelo Instituto Brasileiro de Geografia e Estatística (IBGE, 2000) revelou que no Brasil existem aproximadamente 24 milhões de pessoas que apresentam algum tipo de deficiência. Além disso, nas últimas décadas tem-se observado um número crescente de estudantes com deficiência em todos os níveis de ensino da rede pública e privada. No que diz respeito ao ensino superior, o Censo da Educação Superior de 2017, do Instituto Nacional de Estudos e Pesquisas Educacionais (INEP, 2018) apresentou dados que comprovam um crescimento expressivo da população de pessoas com deficiência que acessam as universidades, em especial de deficientes físicos e visuais. De acordo com Mendes e Ribeiro (2017), políticas de inclusão no ensino superior, tais como o Programa Universidade para Todos, ProUni (BRASIL, 2005), que destina um percentual de bolsas em universidades privadas às pessoas com deficiência, e o Programa de Acessibilidade na Educação Superior - Incluir - (BRASIL, 2007), o qual estabelece normas e critérios para inclusão de um número maior de pessoas com deficiência no meio acadêmico, têm propiciado um acesso mais amplo e uma maior permanência destes sujeitos nas instituições de ensino superior, públicas e privadas. Neste contexto, Castro (2011) destaca que o acesso não deve corresponder apenas ao ingresso à universidade por parte do aluno com deficiência, mas deve englobar desde estratégias de seleção justas até o provimento de condições igualitárias para uma conclusão bem-sucedida do ensino superior.

O direito de que todos os cidadãos participem de maneira igualitária nos espaços educacionais está previsto na Constituição Federal Brasileira de 1988, em especial em seu artigo 206 que estabelece que: "[...] o ensino será ministrado com base nos seguintes princípios: I - igualdade de condições para o acesso e permanência na escola" (BRASIL, 1988, p. 34). Este direito foi reiterado na Lei Brasileira de Inclusão da Pessoa com Deficiência (BRASIL, 2015) e, no contexto do ensino superior, um marco importante para seu exercício foi a Portaria $n^{\circ} 3.284$, de 7 de novembro de 2003, a qual estabelece requisitos de acessibilidade para pessoas com deficiência a fim de que sejam autorizados e reconhecidos novos cursos e credenciadas novas instituições de ensino superior (BRASIL, 2003). Assegurada a educação como um direito de todos, surge então uma demanda por aprimoramento educacional e promover a acessibilidade e a inclusão digital pode auxiliar na garantia de que esse direito seja exercido. Para Lima e Castro (2012, p. 84) "[...] privar qualquer pessoa de conhecer e buscar esse conhecimento é impedir o seu crescimento e a sua formação". Nesse sentido, Silva e Camargo (2018) acrescentam que as pessoas com deficiência, apesar de serem capazes de aprender qualquer tipo de conteúdo ministrado, não têm encontrado condições necessárias

'Braille: sistema de escrita em relevo utilizada por pessoas que não enxergam. 
para uma aprendizagem adequada no contexto escolar, o qual deveria configurar-se no principal ambiente de inclusão.

Uma educação inclusiva visa ao exercício pleno da cidadania, permitindo que todos os alunos, independentemente de seus perfis, participem juntos do processo de ensinoaprendizagem em salas de aula do ensino regular. Para que esse objetivo seja alcançado, a escola ou universidade deve receber igualitariamente a todos os estudantes, considerando suas especificidades, sejam elas inatas ou adquiridas, com fins de valorização da diversidade, evitando a segregação ou homogeneização. Lacueva (1997) afirma que a diversidade é uma vantagem social, pois a partir dela os sujeitos podem aprender uns com os outros. Desta forma, à medida que são realizadas modificações aos espaços físicos de escolas e universidades, a partir da diversidade de seu alunado, novos degraus são trilhados rumo à inclusão de todos os perfis.

Neste sentido, a ampliação das habilidades funcionais da pessoa com deficiência explorando seus talentos tem sido objeto de estudo da Tecnologia Assistiva. Sonza et al. (2013, p. 8) definem Tecnologia Assistiva como "[...] uma área do conhecimento e de pesquisa que tem se destacado pelas possibilidades de propiciar uma maior independência, qualidade de vida e inclusão social das pessoas com deficiência". Assim, as Tecnologias Assistivas podem ser entendidas como produtos e serviços que visam a ampliar as possibilidades de desempenho do ser humano, proporcionando independência e autonomia para realizar desde simples atividades domésticas até tarefas mais complexas, relacionadas ao trabalho e estudos, promovendo, assim, a inclusão do indivíduo. Para Vergara-Nunes $(2016$, p. 91), "[...] a autonomia propiciada pelas tecnologias assistivas às pessoas cegas na realização de suas atividades propicia-Ihes trabalhar, estudar, ou seja, usufruir de todos os seus direitos como os demais cidadãos".

Uma tecnologia assistiva de grande potencial no contexto educacional, a audiodescrição no Brasil ainda é um recurso direcionado à promoção de bens culturais e acesso ao lazer para as pessoas com deficiência visual. Consistindo em uma tradução que transforma imagens em palavras, a partir de critérios de acessibilidade e de acordo com as características do público a que se destina, atualmente ela tem sido também utilizada em sites e redes sociais para descrição de fotos e imagens. Apesar de ainda ser desconhecido de professores e alunos, autores como Franco e Silva (2010) e Motta (2015) defendem que seu uso no ambiente escolar permitirá a remoção de barreiras comunicacionais, equiparando as oportunidades de aprendizado e permitindo o enriquecimento do agir pedagógico.

Camargo, Nardi e Correia (2010) entendem que a inclusão no ambiente escolar e universitário deve levar em consideração as especificidades do conteúdo de ensino, bem como de cada deficiência, servindo como objeto investigativo. Assim, no que diz respeito às ciências naturais e, em especial, à física que utiliza de maneira ampla as referências visuais, é necessário que sejam pensadas novas metodologias de ensino para a inserção desses educandos com vistas a uma alfabetização científica e tecnológica, que lhes permita serem indivíduos autônomos, assumindo seus lugares de direito na sociedade, os quais Ihes foram negados por muito tempo.

Considerando-se a escassez de estudos nacionais que analisem o papel da audiodescrição enquanto ferramenta inclusiva no contexto educacional, e partindo da seguinte indagação: quais as possibilidades e limitações da inserção da audiodescrição na mediação do ensino inclusivo de física nas universidades? este trabalho tem por objetivo 
apresentar um estudo de caso baseado na aplicação desta tecnologia no processo de ensino -aprendizagem de um estudante de graduação em Licenciatura em Física com baixa visão. Será apresentada ainda uma breve revisão da literatura sobre o ensino de física para estudantes com deficiência visual no Brasil e dos referenciais teóricos de Vygostky e metodológico de Yin.

\section{O Ensino de Física no contexto da Deficiência Visual no Brasil}

O Censo da Educação Superior de 2017 (INEP, 2018) informou que, na ocasião, havia o registro de 37.685 alunos com deficiência matriculados em Instituições de Ensino Superior (IES), dos quais $10.619(28,18 \%)$ apresentavam baixa visão e $2.203(5,85 \%)$ eram cegos (Figura 1). Apesar de não haver dados oficiais sobre a distribuição desses estudantes por curso ou área de conhecimento, estudos como o de Almeida, Bellosi e Ferreira (2015) apontam que entre $25 \%$ a $30 \%$ dos alunos com deficiência estão matriculados em cursos da área de Ciências Exatas e Tecnológicas. Portanto, torna-se urgente a inserção de metodologias inclusivas nas aulas de física do ensino superior para contemplar tais estudantes, propiciando a plenitude de sua participação em sala de aula, considerando-se as especificidades da deficiência em si.

Figura 1 - Distribuição do número de alunos por deficiência no ensino superior

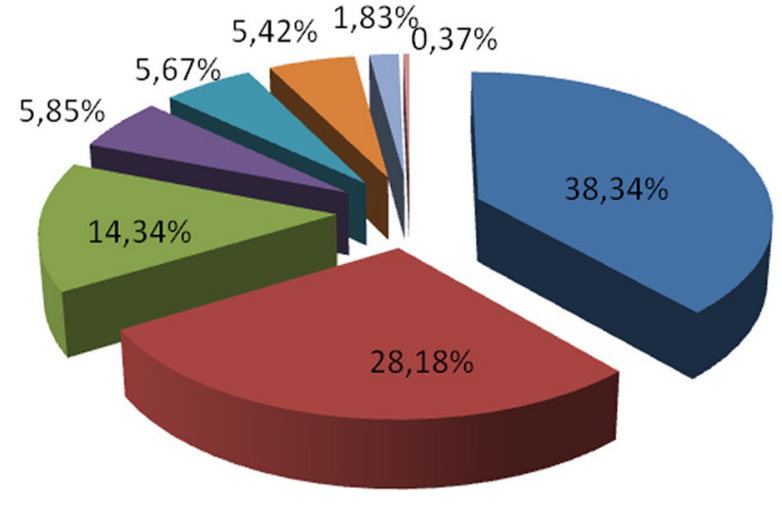

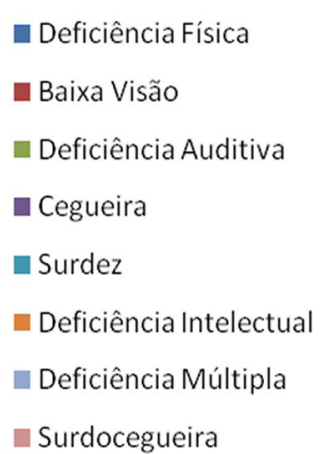

Fonte: censo da educação superior de 2017 (INEP, 2018).

No Brasil, a temática do Ensino de Física para alunos com deficiência visual é relativamente recente, sendo os primeiros trabalhos neste campo datados do início dos anos 2000. Através de uma busca detalhada nas plataformas Scielo e Google Scholar verificouse que, dentre os trabalhos publicados nestas quase duas décadas, sejam em periódicos ou em anais de eventos, grande parte analisa as dificuldades que têm sido enfrentadas por estudantes com deficiência visual (DV) e seus professores no contexto do ensino de física (CAMARGO, 2005; CAMARGO; NARDI, 2008, 2010; CAMARGO; SCALVI, 2003; DICKMAN; FERREIRA, 2008; NEVES et al., 2000). Dentre outros obstáculos, os autores pontuam que são barreiras recorrentes à participação efetiva do estudante com DV nas aulas de física:

- A ausência de uma formação adequada dos professores para lidar com estudantes cegos e de baixa visão, resultado de uma matriz curricular dos cursos de licenciatura que não contempla a diversidade e a inclusão, na maioria dos casos; 
- Metodologias excessivamente visuais. Sem a formação mencionada acima, professores que usam slides, figuras, gráficos, anotações no quadro em geral, que gesticulam ou usam frases como "observem nesta equação..." produzem barreiras comunicacionais à plena atuação do estudante DV, como apontado por Camargo (2010), que sugere uma mudança de referencial visual para outro auditivo-tátil, a fim de contemplar alunos videntes ${ }^{2}$ e não videntes;

- Pouca ou nenhuma experimentação, resultante da carência de recursos adequados, o que torna a física excessivamente matematizada e monótona para os estudantes, com DV ou não (COSTA; NEVES; BARONE, 2006), causando insegurança, desinteresse e desmotivação.

Buscando preencher algumas lacunas na problemática exposta acima, vários pesquisadores têm enfatizado a importância da experimentação como metodologia para inserção deste público no processo de ensinar e aprender. Inúmeros trabalhos propõem material didático experimental adaptado, grande parte deles utilizando material de baixo custo. Maquetes táteis, materiais em relevo e com diferentes cores e texturas têm sido propostos por diversos autores, explorando as mais diversas áreas da física, desde a Mecânica Clássica à Física Moderna (ARAÚJO et al., 2015; CAMARGO, 2007, 2010; HALLAIS; CATARINO; BARBOSA-LIMA, 2017; MENDONÇA, 2015). Salienta-se que, em sua maioria, os trabalhos propõem a realização das atividades em grupos mistos de alunos, incentivando a interação e valorizando a diversidade, mas alguns deles buscam estimular a independência dos discentes com deficiência visual, inserindo-os em todas as etapas da experimentação proposta, desde a montagem até a análise dos dados.

Outra parte relevante dos trabalhos produzidos no Brasil trata da formação de professores para atuar no ensino de física para alunos cegos e de baixa visão, a exemplo de Barbosa-Lima e Castro (2012), Camargo e Nardi (2006), e Salmazo e Rodrigues (2015), os quais analisam as possibilidades e perspectivas de se introduzir o tema nos cursos de licenciatura em física e ciências, seja em disciplinas de instrumentação já existentes na matriz curricular ou a partir de disciplinas novas, criadas para esta finalidade.

Uma característica comum a todas estas pesquisas é o seu público-alvo: alunos com DV dos ensinos fundamental e médio. Aparatos experimentais adaptados, instrumentalização para licenciandos, aplicações de questionários e propostas de sequências didáticas: a maior parte da literatura produzida no Brasil enfoca o ensino de física no contexto da escola regular. Desta forma, entende-se que, se a questão do ensino de física acessível para estudantes com DV ainda é incipiente no Brasil, quando se trata do ensino de física para tais alunos no contexto do nível superior o tema permanece ainda mais inexplorado. No entanto, é importante pontuar que os discentes com DV neste nível de ensino também se deparam com os obstáculos relatados anteriormente, talvez até em maior grau, já que, de maneira geral, os estudantes do nível superior são tidos como mais autônomos e maduros no aspecto educacional. Faz-se necessário, portanto, que essa área seja mais investigada a fim de que se forneça um suporte científico adequado que propicie a melhoria das metodologias existentes, bem como a sugestão de novas intervenções.

2Pessoas que não se enquadram na definição de deficiência visual da Organização Mundial de Saúde. 


\section{Referencial Teórico}

Considerando-se que Vygotsky (1896-1934) é um dos principais estudiosos das teorias cognitivas de aprendizagem, e que suas contribuições são significativas para a educação de pessoas com deficiências, em especial no âmbito da surdez, cegueira e da deficiência intelectual, este trabalho baseia-se em sua teoria histórico-cultural como elemento teórico norteador. Em sua perspectiva, a diversidade humana se sobrepõe aos padrões de normalidade e, segundo o autor, "[...] o funcionamento psíquico das pessoas com deficiência obedece às mesmas leis, embora com uma organização distinta das pessoas sem deficiência" (NUERNBERG, 2008, p. 3). Vygotsky (apud Nuernberg, 2008) também considera que, além da deficiência primária, de ordem biológica, existe outra secundária, que envolve as consequências psicossociais da primeira, resultando em barreiras educacionais, atitudinais e físicas, as quais acentuam e consolidam a própria deficiência. Tendo sido um crítico contumaz da segregação, em todas as suas formas, imposta às pessoas com deficiência, Vygotsky considerava as metodologias de ensino fundamentadas em limitações intelecto-sensoriais como obstáculos ao desenvolvimento deste público. Segundo Nuernberg (2008, p. 3), com a aplicação deste tipo de metodologias "[...] cria-se, assim, um círculo vicioso no qual, ao não se acreditar na capacidade de aprender das pessoas com deficiência, não lhe são ofertadas condições para superarem suas dificuldades". Na concepção de Vygotsky, o sistema nervoso central e o mecanismo psíquico do indivíduo com deficiência compensam o funcionamento insuficiente do órgão afetado, no que ele chamou de compensação social. De acordo com Bianchetti, Da Ros e Deitos (2000), a maioria dos próprios indivíduos cegos percebe sua cegueira como limitação e, no caso da cegueira adquirida, a partir do momento em que se perde o sentido da visão, eles estabelecem um mecanismo de coleta de informações a partir dos demais sentidos, no processo de compensação social. Como ressalta Camargo (2010), no caso de uma pessoa cega, não é o tato ou o ouvido que se tornam superdesenvolvidos, mas toda a personalidade do indivíduo é afetada, com a finalidade de vencer o conflito social através da super compensação, não com o objetivo de substituir a visão. Assim, para Vygotsky (1989, p. 5 apud BIANCHETTI; DA ROS; DEITOS, 2000, p. 44) "[...] qualquer defeito origina estímulos para a formação da compensação".

Vygotsky (1997) também acreditava que o pensamento coletivo é a principal fonte de compensação da cegueira, pois, através dele, seria possível eliminar as suas consequências secundárias e, assim, fornecer possibilidades ilimitadas de desenvolvimento à criança cega. Portanto, a partir da concepção de que o desenvolvimento do indivíduo se dá mediante a interação histórico-social, Vygotsky afirma que a compensação produz novas estratégias de aprendizagem, as quais propiciam o desenvolvimento do sujeito com deficiência. Diante do exposto, entendemos que através das tecnologias assistivas existentes seja viável a materialização da compensação social em estudantes com DV, de modo a propiciar sua inclusão em escolas, universidades, trabalho e na sociedade como um todo. Assim, para que haja uma incorporação significativa de tais tecnologias ao processo de ensino-aprendizagem, é necessário que antes se promova o entendimento da acessibilidade em si, o que requer uma mudança de mentalidade, evitando a segregação. Neste contexto, Pupo, Melo e Pérez Férres (2006) relatam a urgência de, no atual mundo globalizado, contemplar a diversidade humana, com vistas à inclusão de todos, considerando que o avanço das Novas Tecnologias de Informação e Comunicação (NTIC) altera o cotidiano do ensino e da aprendizagem nas escolas e universidades. 
Dentre as principais tecnologias assistivas utilizadas para o ensino do indivíduo cego e de baixa visão, de maneira geral, estão os softwares ampliadores e leitores de tela, impressoras Braille, livros e apostilas ampliados, material didático em Braille, maquetes táteis e materiais em relevo, com cores e texturas diferentes. Uma alternativa para a remoção das barreiras comunicacionais decorrentes do uso de imagens, vídeos, simulações e outros recursos visuais por parte de professores em turmas com alunos com DV é a utilização da audiodescrição, conforme discutido adiante.

\section{Metodologia}

Neste trabalho, nosso foco está na aplicação do recurso de audiodescrição ao material didático acessível das disciplinas de física para os estudantes com DV, no que diz respeito a gráficos, tabelas e equações, específicos deste material, os quais não são lidos a dequadamente pelos leitores de tela existentes no mercado, como analisou Carvalho (2015) através de um levantamento detalhado desses softwares. Buscando fornecer mais autonomia ao aluno com DV no ensino superior, investigamos de que forma o material audiodescrito pode contribuir para o processo de ensino-aprendizagem, quando combinado com as tecnologias assistivas usuais, a saber, maquetes táteis e materiais didáticos ampliados, em relevo ou em Braille.

Assim, a presente pesquisa caracteriza-se como um estudo de caso, de caráter qualitativo e descritivo, tendo sido a coleta de dados realizada em ambiente natural, entre outubro de 2016 e outubro de 2017.

De acordo com Müller (2013), a pesquisa qualitativa tem caráter exploratório, construtivo e descritivo e, a partir dela, o pesquisador fundamenta a teoria e produz novas hipóteses, por meio dos dados, que podem ser coletados a partir de observações, entrevistas, aplicação de questionários, etc. Portanto, a pesquisa qualitativa busca analisar as diversas maneiras de manifestação do objeto de estudo e se baseia em um exemplo dialético de análise (CAMARGO; NARDI, 2007).

Desta maneira, para a realização deste estudo optamos pelo estudo de caso como metodologia de pesquisa, mais especificamente na perspectiva de Robert K. Yin (YIN, 2001), o qual define o estudo de caso como uma investigação empírica de um fenômeno contemporâneo em seu contexto da vida real. De acordo com Yin (2001), o estudo de caso permite uma investigação integral dos fenômenos na realidade quando o pesquisador dispõe de pouco ou nenhum controle para alterar ações relevantes. Além disso, se distingue de outras pesquisas, pois pode se ocupar de diversas evidências, documentos, observações e entrevistas.

Ainda segundo o autor, o estudo de caso é composto pela definição do problema, planejamento da pesquisa, coleta e análise de dados, seguida da composição e da apresentação dos resultados. No que se refere aos estudos de um único caso, estes podem ser descritos de modo simplificado, podendo conter tabelas, gráficos ou imagens, enquanto que o banco de dados compreende os registros realizados pelo pesquisador das entrevistas, observações e outros documentos. Já o relatório do pesquisador pode ser escrito em forma de artigo, como realizado nesta publicação. 
Para Yin (2001), o estudo de caso pode ser categorizado de três formas, a saber: (a) exploratório: aquele cuja finalidade é adquirir informações acerca do problema de interesse; (b) descritivo: o estudo de caso que tem por objetivo descrever de maneira aprofundada o caso sob análise; e, (c) explanatório: aquele cujo propósito central é confrontar teorias estabelecidas com proposições teóricas sugeridas no estudo. É importante salientar que, na perspectiva de Yin, um caso é um componente qualquer de um todo, claramente identificável, tal como uma pessoa, uma sala de aula, um evento, organização, atividade, processo, etc. (MÜLLER, 2013). Portanto, esta pesquisa, de acordo com a perspectiva de Yin, pode ser caracterizada como um estudo de caso descritivo e teve como unidade um estudante com baixa visão, do quinto período do curso de Licenciatura em Física, na modalidade à distância, de uma universidade pública federal situada na região Nordeste brasileira e sua tutora presencial, que possui formação em Licenciatura em Física.

Esta pesquisa foi realizada entre outubro de 2016 e outubro de 2017, período em que as autoras fizeram o acompanhamento das atividades do estudante e de sua tutora e, como ponto de partida, observou-se o histórico escolar do discente, o qual apresentava muitas reprovações e alguns trancamentos de disciplinas. Neste primeiro momento foi verificado que o estudante utilizava o material didático ampliado, fornecido pelo setor de acessibilidade da universidade e, por iniciativa própria, sua tutora realizava algumas atividades experimentais com material adaptado.

Posteriormente, como o estudante encontrava-se em progressiva perda de visão, a universidade passou a fornecer material didático digital e um computador com software leitor de tela, para o qual o aluno obteve um treinamento de utilização e relatou algumas dificuldades iniciais, sendo a principal delas o fato de que o programa não conseguia fazer a leitura de elementos gráficos, tais como equações, tabelas e figuras, o que comprometia seriamente sua compreensão do conteúdo e o tornava ainda mais dependente da tutora, que precisava fazer a leitura e análise destes elementos com ele nos encontros presenciais, tempo que, segundo a própria tutora, eles deveriam utilizar para a resolução de exercícios e esclarecimentos de dúvidas.

Em um segundo momento, procedeu-se à confecção dos gráficos e figuras em material tátil, usando papel de alta densidade, cola 3D e cordões diversos. No entanto, essa medida emergencial revelou-se contraproducente, uma vez que a quantidade de elementos no material didático era vasta e a confecção de suas versões táteis não conseguia acompanhar o avanço das aulas do discente, pois o semestre letivo já estava em curso. Assim, sob autorização do setor de acessibilidade e, após algumas instruções acerca do processo de audiodescrição por profissionais do referido setor, iniciamos a audiodescrição do material didático do curso de Licenciatura em Física. A princípio, foram audiodescritos os materiais das disciplinas nas quais o aluno já se encontrava matriculado bem como daquelas em que iria matricular-se no semestre seguinte, mas posteriormente foram audiodescritas todas as disciplinas da matriz curricular do curso de Licenciatura em Física, na modalidade à distância.

Paralelamente ao uso da audiodescrição, o discente e sua tutora continuaram utilizando, em menor escala, o material tátil adaptado, mais como forma de fazer com que o discente se habituasse à transição do referencial visual para o tátil-auditivo. Assim, foram analisados três momentos distintos: o primeiro, quando o estudante utilizou apenas material 
ampliado e em relevo; o segundo, em que o discente usou o material digital com auxílio do leitor de tela mais o material em relevo, e o terceiro, em que foram aplicados a audiodescrição e o material em relevo combinados.

Ao término do período de realização da pesquisa, as autoras a plicaram um questionário semiestruturado ao discente e sua tutora, em momentos distintos, a fim de verificar suas impressões sobre cada uma das etapas e metodologias utilizadas, conforme será discutido a seguir.

\section{Resultados e Discussões}

Para entender as opiniões do estudante com deficiência visual e da tutora acerca do processo ensinar/aprender física utilizando diferentes tecnologias assistivas, aplicamos um questionário semiestruturado a cada um deles, em momentos separados, a fim de que a fala de um não sugestionasse as impressões do outro. Salienta-se que seguiremos o procedimento para análise dos dados qualitativos de Costa, Neves e Barone (2006), ou seja, traçaremos um padrão ideográfico ${ }^{3}$ das considerações de cada entrevistado, mantendo apenas as unidades de significado ${ }^{4}$ e identificando possíveis convergências nas ideias expostas por cada sujeito, as quais são apresentadas nos Quadros que seguem.

Quadro 1 - Considerações do discente com DV e sua tutora sobre a primeira fase analisada: material didático ampliado e em relevo

\begin{tabular}{|l|l|}
\hline Discente & $\begin{array}{l}\text { Antes de receber o material digital acompanhado do leitor de tela, contava com a ajuda de uma colega } \\
\text { de curso vidente em meus estudos. }\end{array}$ \\
\hline Tutora & $\begin{array}{l}\text { Antes da audiodescrição, em cada semestre, ele estava matriculado em quatro ou cinco disciplinas } \\
\text { e era sempre reprovado em alguma. O tempo não era suficiente para se dedicar a todas e, também, } \\
\text { pelo fato de ser preciso eu ler e adaptar algumas imagens para que ele compreendesse o conteúdo. }\end{array}$ \\
\hline
\end{tabular}

Fonte: elaborado pelas autoras.

É possível perceber na fala dos dois entrevistados uma convergência, pois na primeira etapa do processo de introdução das tecnologias assistivas aos estudos do educando com DV, havia grande dependência dele em relação aos colegas e à tutora presencial. Essa dependência contribuiu negativamente para sua autonomia e seu rendimento escolar, como ilustra a fala da tutora, ao relatar pelo menos uma reprovação em cada semestre letivo. Desta forma, pode-se afirmar que o material ampliado e os esforços da tutora na construção de materiais em relevo não estavam sendo suficientes para garantir um aprendizado efetivo de todas as disciplinas em que o aluno se matriculava a cada semestre, ficando uma ou duas delas sempre em segundo plano, o que ocasionava reprovações.

Em relação à segunda etapa de introdução das tecnologias assistivas, referente ao uso do leitor de tela (NVDA, 2019) com o material digital, ambos relatam melhora no desempenho acadêmico do discente, mas com algumas dificuldades ainda observadas, como ilustrado por suas falas apresentadas no Quadro que segue.

\footnotetext{
${ }^{3}$ No sentido de representação de ideias.

${ }^{4}$ Unidades extraídas das falas que contêm suas possíveis essencialidades.
} 
Quadro 2 - Considerações do discente com DV e sua tutora sobre a segunda fase analisada: leitor de tela e maquetes táteis

\begin{tabular}{|l|l|}
\hline Discente & $\begin{array}{l}\text { As equações e tabelas contidas no material didático não estavam sendo lidos pelo programa, assim, } \\
\text { como forma de complementar aos estudos, pesquisava e utilizava os recursos de videoaulas do Youtube. }\end{array}$ \\
\hline Tutora & $\begin{array}{l}\text { Após a adaptação do material com o leitor de tela, os encontros passaram a ser mais produtivos, pois } \\
\text { o aluno estudava em casa e levava apenas as dúvidas, mas grande parte delas se referia aos elementos } \\
\text { não textuais do material didático, que não estavam sendo lidos pelo programa. }\end{array}$ \\
\hline
\end{tabular}

Fonte: elaborado pelas autoras.

Das colocações feitas pelos dois sujeitos entrevistados, vemos que, diante da dificuldade apresentada pelo leitor NVDA com os elementos gráficos, o próprio estudante com DV buscou alternativas para superá-las através da tecnologia, neste caso, da internet, o que pode ser considerado um esforço de compensação social, na abordagem de Vygotsky, o qual afirma que qualquer limitação pode se configurar em estímulo ao mecanismo de compensação. A fala da tutora, por sua vez, deixa claro o avanço observado por ela na autonomia do estudante após a introdução do leitor de tela, mas também pontua as restrições de seu uso.

Ao começar a usar o material audiodescrito, o estudante passa a ser de fato autônomo e mais independente, como ressaltam as suas considerações mostradas no Quadro 3.

Quadro 3 - Considerações do discente com DV e sua tutora sobre a terceira fase analisada: audiodescrição e maquetes táteis

\begin{tabular}{|l|l|}
\hline Discente & $\begin{array}{l}\text { Considero a audiodescrição fundamental para minha autonomia nos estudos, já utilizo o leitor de } \\
\text { tela sozinho no computador e me sinto seguro quanto ao seu uso, não necessitando de assistência. } \\
\text { Quanto à plataforma o o SIGAA, acho que apresentam barreiras, dificultando a localização do material } \\
\text { disponibilizado pelos professores e também a realização de provas. Em algumas situações, a prova } \\
\text { online tinha apenas o enunciado da questão lido pelo NVDA, não permitindo a leitura das alternativas. }\end{array}$ \\
\hline Tutora & $\begin{array}{l}\text { Acho que a audiodescrição é um recurso importantíssimo para a aprendizagem do aluno, que passou } \\
\text { a ser mais autônomo nos estudos. Graças a sua maior autonomia, no semestre atual (2017.2) estamos } \\
\text { nos dedicando mais à disciplina de estágio. Eu senti a necessidade de apoiá-lo nesse quesito e selecionei } \\
\text { uma turma mais madura para ele estagiar, na escola onde trabalho. }\end{array}$ \\
\hline
\end{tabular}

Fonte: elaborado pelas autoras.

Agora, sentindo-se melhor atendido por seu material didático acessível, ele sugere, espontaneamente, que aprimoramentos de acessibilidade também sejam feitos no site institucional da universidade e portal do aluno, com os quais ele permanecia tendo dificuldades de acesso e de envio de suas avaliações. Já a tutora reforça as palavras do estudante no que diz respeito à sua maior independência nos estudos. É importante frisar em suas considerações o fato de que o estudante praticamente não a procura mais para obter esclarecimentos quanto ao material didático e eles passaram a utilizar o tempo dos encontros presenciais com mais produtividade, dedicando-se agora às disciplinas de estágio, que se configuram em outro obstáculo ao aluno de licenciatura com DV, para o qual outras intervenções podem ser propostas em trabalhos futuros.

A inquietação, tanto do discente quanto de sua tutora em relação à atuação do primeiro nas disciplinas de estágio, aparece novamente ao final da entrevista, quando ambos foram convidados a dar sugestões, fazer críticas ou suas considerações finais acerca 
do processo de introdução da audiodescrição como tecnologia assistiva. Essas considerações finais estão apresentadas no Quadro 4, e reforçam a necessidade de se realizar uma pesquisa mais aprofundada que aborde o tema e proponha intervenções a fim de que os estudantes com deficiência visual dos cursos de licenciaturas possam atuar de maneira autônoma neste campo, não sendo objeto de análise do presente estudo.

Quadro 4 - Considerações finais do discente com DV e sua tutora sobre o uso das tecnologias assistivas no processo de ensino-aprendizagem da física: sugestões, críticas, etc.

\begin{tabular}{|l|l|}
\hline Discente & $\begin{array}{l}\text { Gostaria que o material audiodescrito fosse enviado para mim antes do começo do semestre. Também } \\
\text { senti muitas dificuldades na disciplina de estágio supervisionado, pois a turma não compreendia } \\
\text { minha deficiência e parecia rir ou ter preconceito. Pensei em abandonar a graduação depois disso, } \\
\text { mas graças aos meus colegas de curso ea à tutora, estou continuando. }\end{array}$ \\
\hline Tutora & $\begin{array}{l}\text { De maneira geral, percebi grandes avanços no aprendizado do estudante após a inserção da } \\
\text { audiodescrição. Apenas gostaria de uma maior orientação para que eu possa auxiliá-lo melhor na } \\
\text { disciplina de Estágio III, além de estratégias para que o aluno possa ter autonomia na sala de aula } \\
\text { como professor, pois é um grande desafio para um aluno cego de licenciatura ministrar e preparar } \\
\text { uma aula, por exemplo, para a elaboração de uma apresentação em PowerPoint. }\end{array}$ \\
\hline
\end{tabular}

Fonte: elaborado pelas autoras.

É importante enfatizar o preconceito que o estudante relata ter presenciado ao atuar em uma sala de aula como professor pela primeira vez e como isso quase o fez desistir do curso, caracterizando os efeitos secundários da deficiência, mencionados por Vygotsky ao longo de sua obra e que são de caráter psicossocial. Apesar de ter aprendido os princípios da física necessários para ministrar a aula em questão e como fazê-lo, por meio das disciplinas pedagógicas, fatos atestados pelas aprovações em seu histórico acadêmico, o estudante se sentiu inapto a realizar tal tarefa, pois era assim que os seus alunos o percebiam. Por outro lado, as sugestões finais da tutora reforçam o que defendem Barbosa-Lima e Gonçalves (2014) quando afirmam que é necessário pensar de que forma se pode contribuir para a formação docente do licenciando em Física, no que diz respeito a indicar os caminhos de uma prática docente transformadora e inclusiva.

\section{Conclusões}

Neste trabalho apresentamos um estudo de caso acerca da introdução da audiodescrição como tecnologia assistiva no processo de ensino-aprendizagem de um estudante de baixa visão do curso de Licenciatura em Física na modalidade à distância. Através de uma abordagem teórica fundamentada no referencial histórico-cultural de Vygotsky e de uma metodologia qualitativa de estudo de caso sob a ótica de Yin, verificamos que a aplicação da audiodescrição no contexto educacional pode proporcionar a redução das barreiras comunicacionais, permitindo que os alunos sejam mais participativos, críticos e autônomos, refletindo de maneira positiva em seu rendimento acadêmico e influenciando diretamente na sua atuação enquanto cidadãos. Para Cozendey e Costa $(2018$, p. 1), "[...] a audiodescrição, além de ser um recurso de ensino importante para pessoas cegas e com baixa visão, pode facilitar a compreensão ou explicação de um conceito a alunos que não apresentam limitações visuais", demonstrando, assim, a aplicabilidade desta ferramenta em turmas mistas. 
Apesar de uma melhora acentuada no aprendizado do estudante, atestada por ele mesmo, por sua tutora presencial e pela verificação de seu histórico escolar, é necessário destacar que a audiodescrição, por si só, não garante o aprendizado dos conteúdos ministrados, servindo como auxiliar ao processo de ensino-aprendizagem. Neste trabalho, ela foi introduzida em conjunto com a utilização de material em relevo e maquetes táteis. É preciso, portanto, que haja um acompanhamento do discente por parte do professor ou tutor para verificar se houve um entendimento correto dos conceitos e fundamentos ou se o estudante compreendeu de maneira errônea, sendo necessário reforçar alguma informação (COZENDEY; COSTA, 2018). Assim, caso esse reforço seja necessário, o professor/tutor pode mudar do referencial auditivo para o tátil, promovendo uma melhor fixação dos conteúdos estudados, semelhantemente ao que ocorre nas intervenções mediante a interação professor/ aluno vidente.

Desta forma, a aplicação da audiodescrição não visa suprir o papel de mediador do professor nem tampouco substituir as demais opções metodológicas e de material didático, mas sim complementá-las e propiciar uma maior independência do estudante com deficiência visual em seus estudos, permitindo-Ihe oportunidades de desempenho e desenvolvimento pessoal semelhante às dos demais alunos, conforme previsto na nossa legislação.

Por fim, pontuamos que a redução da barreira comunicacional possibilitada pelo uso da audiodescrição não é capaz, sozinha, de remover outros obstáculos de inclusão enfrentados pelos estudantes com DV no ensino superior. Barreiras arquitetônicas e tecnológicas, professores sem a devida formação para lidar com esse alunado, preconceitos e segregação ainda persistem no ambiente de escolas e universidades e faz-se necessário que o campo de pesquisa do ensino de física para pessoas com deficiência visual, ainda incipiente no Brasil, se expanda para incluir estes e outros desafios, propondo as devidas intervenções com o objetivo de superá-los ou, ao menos, minimizá-los.

\section{Referências}

ALMEIDA, J. G. A.; BELLOSI, T. C.; FERREIRA, E. L. Evolução da matrícula de pessoas com deficiência na educação superior brasileira: subsídios normativos e ações institucionais para acesso e permanência. Revista Ibero-americana de Estudos em Educação, Araraquara, v. 10, n. esp., p. 643-660, 2015. DOI: https://doi.org/10.21723/riaee.v10i5.7917.

ARAÚJO, I. S.; ELIAS FILHO, M. R.; SILVA, M. D. B.; CASTRO, S. M. V.; YANO, V. T. B. Ensino de física para deficientes visuais: a importância do uso de experimentos em sala de aula. Revista Brasileira de Ensino de Ciências Naturais, Belém, v. 1, n. 1, p. 78-86, 2015. Disponível em: https://periodicos.uepa. br/index.php/rbecn/article/view/489. Acesso em: 8 set. 2020.

BARBOSA-LIMA, M. C. A.; CASTRO, G. F. Formação inicial de professores de física: a questão da inclusão de alunos com deficiências visuais no ensino regular. Ciência \& Educação, Bauru, v. 18, n. 1, p. 81-98, 2012. DOI: https://doi.org/d9p2.

BARBOSA-LIMA, M. C.; GONÇALVES, C. O. O ensino não formal e a formação de um professor de física para deficientes visuais. Ensaio, Belo Horizonte, v. 16, n. 2, p. 167-184, 2014. DOI: https://doi. org/d9p3.

BIANCHETTI, L.; DA ROS, S. Z.; DEITOS, T. P. As novas tecnologias, a cegueira e o processo de compensação social em Vygotsky. Ponto de Vista, Viçosa, v. 2, n. 2, p. 41-47, 2000. Disponível em: https://periodicos.ufsc.br/index.php/pontodevista/article/view/1537. Acesso em: 8 set. 2020. 
BRASIL. [Constituição (1988)]. Constituição da República Federativa do Brasil. Brasília: Senado Federal, [1988]. Disponível em: http://www.senado.leg.br/atividade/const/constituicao-federal.asp\#/. Acesso em: 14 jul. 2019.

BRASIL. Lei n. 11.096, de 13 de janeiro de 2005. Institui o Programa Universidade para Todos (ProUni), regula a atuação de entidades beneficentes de assistência social no ensino superior; altera a Lei n. 10.891, de 9 de julho de 2004, e dá outras providências. Diário Oficial da República Federativa do Brasil: seção I, Brasília, n. 10, p. 7, 14 jan. 2005.

BRASIL. Lei no 13.146, de 06 de julho de 2015. Institui a lei brasileira de inclusão da pessoa com deficiência (estatuto da pessoa com deficiência). Diário Oficial da República Federativa do Brasil, Brasília, 7 jul. 2015. Disponível em: http://www.planalto.gov.br/ccivil_03/_ato2015-2018/2015/lei/ I13146.htm. Acesso em: 1 set. 2019.

BRASIL. Portaria n. 14, de 24 abril de 2007. Dispõe sobre a criação do Programa Incluir: acessibilidade na educação superior. Diário Oficial da República Federativa do Brasil: seção I, Brasília, n. 80, p. 4, 26 abr. 2007.

BRASIL. Portaria n 3.284, de 7 de novembro de 2003. Dispõe sobre requisitos de acessibilidade de pessoas portadoras de deficiências, para instruir os processos de autorização e de reconhecimento de cursos, e de credenciamento de instituições. Diário Oficial da República Federativa do Brasil: seção I, Brasília, p. 12, 11 nov. 2003.

CAMARGO, E. P. A comunicação como barreira à inclusão de alunos com deficiência visual em aulas de mecânica. Ciência \& Educação, Bauru, v. 16, n. 1, p. 259-275, 2010. DOI: https://doi.org/fkkx9q.

CAMARGO, E. P. É possível ensinar física para alunos cegos ou com pouca visão?: proposta de atividades de física que enfocam o conceito de aceleração. Física na Escola, Rio de Janeiro, v. 8, n. 1, p. 30-34, 2007.

CAMARGO, E. P. O ensino de física no contexto da deficiência visual: elaboração e condução de atividades de ensino de física para alunos cegos e com baixa visão. 2005. 289 f. Tese (Doutorado em Educação) - Faculdade de Educação, Universidade Estadual de Campinas, Campinas, 2005. Disponível em: http://repositorio.unicamp.br/jspui/handle/REPOSIP/252902. Acesso em: 8 set. 2020.

CAMARGO, E. P.; NARDI, R. Contextos comunicacionais adequados e inadequados à inclusão de alunos com deficiência visual em aulas de mecânica. Ensaio, Belo Horizonte, v. 12, n. 2, p. 27-48, 2010. DOI: https://doi.org/d9p4.

CAMARGO, E. P.; NARDI, R. Dificuldades e alternativas encontradas por licenciandos para o planejamento de atividades de ensino de eletromagnetismo para alunos com deficiência visual. Investigações em Ensino de Ciências, Porto Alegre, v. 12, n. 1, p. 55-69, 2007. Disponível em: https:// www.if.ufrgs.br/cref/ojs/index.php/ienci/article/view/477. Acesso em: 8 set. 2020.

CAMARGO, E. P.; NARDI, R. O emprego de linguagens acessíveis para alunos com deficiência visual em aulas de óptica. Revista Brasileira de Educação Especial, Marília, v. 14, n. 3, p. 405-426, 2008. DOI: https://doi.org/10.1590/S1413-65382008000300006.

CAMARGO, E. P.; NARDI, R. Ensino de conceitos físicos de termologia para alunos com deficiência visual: dificuldades e alternativas encontradas por licenciandos para o planejamento de atividades. Revista Brasileira de Educação Especial, Marília, v. 12, n. 2, p. 149-168, 2006. DOl: https://doi.org/ cnm89d.

CAMARGO, E. P.; NARDI, R.; CORREIA, J. N. A comunicação como barreira à inclusão de alunos com deficiência visual em aulas de física moderna. Revista Brasileira de Pesquisa em Educação em Ciências, Belo Horizonte, v. 10, n. 2, 2010. Disponível em: https://periodicos.ufmg.br/index.php/rbpec/article/ view/3981. Acesso em: 15 jun. 2019.

CAMARGO, E. P.; SCALVI, L. V. A. O ensino de física e os portadores de deficiência visual: aspectos observacionais não-visuais de questões ligadas ao repouso e ao movimento dos objetos. In: NARDI, R. Educação em ciências da pesquisa à prática docente. São Paulo: Escrituras, 2003. p.117-133. 
CARVALHO, J. C. Q. Ensino de física e deficiência visual: possibilidades do uso do computador no desenvolvimento da autonomia de alunos com deficiência visual no processo de inclusão escolar. 2015. 256 f. Tese (Doutorado em Ensino de Física) - Instituto de Física, Universidade de São Paulo, São Paulo, 2015. Disponível em: https://teses.usp.br/teses/disponiveis/81/81131/tde-21082015173525/es.php. Acesso em: 10 set. 2020.

CASTRO, S. F. Ingresso e permanência de alunos com deficiência em universidades brasileiras. 2011. 278 f. Tese (Doutorado em Educação Especial) - Centro de Educação e Ciências Humanas, Universidade Federal de São Carlos, São Carlos, 2011. Disponível em: https://repositorio.ufscar.br/handle/ ufscar/2878. Acesso em: 10 set. 2020.

COSTA, L. G.; NEVES, M. C. D.; BARONE, D. A. C. O ensino de física para deficientes visuais a partir de uma perspectiva fenomenológica. Ciência \& Educação, Bauru, v. 12, n. 2, p. 143-153, 2006. DOI: https://doi.org/10.1590/S1516-73132006000200003.

COZENDEY, S. G.; COSTA, M. P. R. Utilizando a audiodescrição como um recurso de ensino. Revista Ibero-Americana de Estudos em Educação, Araraquara, v. 13, n. 3, p. 1164-1186, 2018. DOI: https://doi. org/10.21723/riaee.v13.n3.2018.9626.

DICKMAN, A. G.; FERREIRA, A. C. Ensino e aprendizagem de física a estudantes com deficiência visual: desafios e perspectivas. Revista Brasileira de Pesquisa em Educação em Ciências, Belo Horizonte, v. 8, n. 2, 2008. Disponível em: https://periodicos.ufmg.br/index.php/rbpec/article/ view/4020. Acesso em: 12 ago. 2019.

FRANCO, E. P. C.; SILVA, M. C. C. C. Audiodescrição: um breve passeio histórico. In: MOTTA, L.; ROMEU FILHO, P. (org.). Audiodescrição: transformando imagens em palavras. São Paulo: Secretaria dos Direitos da Pessoa com Deficiência do Estado de São Paulo, 2010. p. 19-36.

HALLAIS, S. C.; CATARINO, G. F. C.; BARBOSA-LIMA, M. C. A. Experimentos adaptados para estudantes com deficiência visual. Revista de Educação, Ciências e Matemática, Rio de Janeiro, v. 7, n. 2, p. 220231, 2017. Disponível em: http://publicacoes.unigranrio.edu.br/index.php/recm/article/view/4509. Acesso em: 10 set. 2020.

IBGE. Censo demográfico: 2000. Rio de Janeiro: IBGE, 2001.

INEP. Censo da educação superior. [2018]. Disponível em: http://inep.gov.br/censo-da-educacaosuperior. Acesso em: 3 maio 2019.

LACUEVA, A. La evaluación en la escuela: una ayuda para seguir aprendiendo. Revista da Faculdade de Educação, São Paulo, v. 23, n. 1-2, p. 124-148, 1997. DOI: https://doi.org/cg9qxz.

MENDES, C. L.; RIBEIRO, S. M. Inclusão da pessoa com deficiência no ensino superior: um estudo da produção acadêmica na área da educação. Atos de Pesquisa em Educação, Blumenau, v. 12, n. 1, p. 189-206, 2017. DOI: https://doi.org/10.7867/1809-0354.2017v12n1p189-206.

MENDONÇA, A. S. Desenvolvimento e aplicação de uma maquete sobre as leis de Kepler para inclusão de alunos com deficiência visual no ensino de física. 2015. 103 f. Dissertação (Mestrado em Ensino de Física) - Faculdade de Ciências e Tecnologia, Universidade Estadual Paulista, Presidente Prudente, 2015. Disponível em: https://repositorio.unesp.br/handle/11449/132927. Acesso em: 9 set. 2020.

MOTTA, L. M. V. M. Audiodescrição na escola: abrindo caminhos para leitura de mundo. Campinas: Pontes, 2015.

MÜLLER, M. G. Metodologias interativas de ensino na formação de professores de física: um estudo de caso com o peer instruction. 2013. 226 f. Dissertação (Mestrado em Ensino de Física) - Instituto de Física, Universidade Federal do Rio Grande do Sul, Porto Alegre, 2013. Disponível em: https://www. lume.ufrgs.br/handle/10183/72092. Acesso em: 9 set. 2020. 
NEVES, M. C. D.; COSTA, L. G.; CASICAVA, J.; CAMPOS, A. Ensino de física para portadores de deficiência visual: uma reflexão. Revista Benjamin Constant, Rio de Janeiro, v. 6, n. 16, 2000. Disponível em: http://www.ibc.gov.br/revistas/211-edicao-16-agosto-de-2000. Acesso em: 23 jun. 2019.

NUERNBERG, A. H. Contribuições de Vigotski para a educação de pessoas com deficiência visual. Psicologia em Estudo, Maringá, v. 13, n. 2, p. 307-316, 2008. DOI: https://doi.org/ct8jcm.

NVDA: non visual desktop access. Disponível em: nvda.pt/pt-pt/downloads. Acesso em: 12 out. 2019.

PUPO, D. T.; MELO, A. M.; PÉREZ FÉRRES, S. (org.) Acessibilidade: discurso e prática no cotidiano das bibliotecas. Campinas: UNICAMP: Biblioteca Central César Lattes, 2006.

SALMAZO, R. S.; RODRIGUES, M. I. R. Formação de professores: ensino de física para cegos através de atividades em relevo. Revista Interacções, Lisboa, v. 39, p. 130-137, 2015. DOI: https://doi. org/10.25755/int.8727.

SILVA, M. R.; CAMARGO, E. P. O atendimento pedagógico especializado e o ensino de física: uma investigação acerca do processo de ensino e aprendizagem de uma aluna cega. Ensaio, Belo Horizonte, v. 20, n. 2894, p. 1-23, 2018. DOI: https://doi.org/10.1590/1983-21172018200102.

SONZA, A. P.; KADE, A.; FAÇANHA, A.; REZENDE, A. L. A.; NASCIMENTO, G. S.; ROSITO, M. C.; BORTOLINI, S.; FERNANDES, W. L. (org.). Acessibilidade e tecnologia assistiva: pensando a inclusão sociodigital de pessoas com necessidades especiais. Bento Gonçalves: IFRS, 2013.

VERGARA-NUNES, E. Audiodescrição didática. 2016. 411 f. Tese (Doutorado em Engenharia e Gestão do Conhecimento) - Centro Tecnológico, Universidade Federal de Santa Catarina, Florianópolis, 2016. Disponível em: https://repositorio.ufsc.br/xmlui/handle/123456789/167796. Acesso em: 10 set. 2020.

VYGOTSKI, L. S. El niño ciego. In: Vygotski, L. S. Obras escogidas V: fundamentos de defectología. Madrid: Visor, 1997. p. 213-234.

YIN, R. K. Estudo de caso: planejamento e métodos. 2 ed. São Paulo: Bookman, 2001. 